\title{
Four-week short chain fructo-oligosaccharides ingestion leads to increasing fecal bifidobacteria and cholesterol excretion in healthy elderly volunteers
} Yoram Bouhnik*1, Lotfi Achour ${ }^{2}$, Damien Paineau ${ }^{3}$, Michel Riottot ${ }^{4}$, Alain Attar ${ }^{1}$ and Francis Bornet ${ }^{3}$

\begin{abstract}
Address: 'Pôle des Maladies de l'Appareil Digestif (PMAD), Service de Gastroentérologie et d'Assistance Nutritive, Hôpital Beaujon, 100 bd du Général Leclerc, 92110 Clichy Cedex, France, ${ }^{2}$ Institut Supérieur de Biotechnologie, avenue Taher El HADED, BP.74, 5000 Monastir, Tunisia , ${ }^{3}$ Nutri-Health SA, Immeuble Ampère, 8 rue Eugène et Armand Peugeot, 92566 Rueil-Malmaison Cedex, France and ${ }^{4}$ Université Paris Sud, Laboratoire de Physiologie de la Nutrition, Bat. 447, 91405 ORSAY Cedex, France

Email: Yoram Bouhnik* - yoram.bouhnik@bjn.aphp.fr; Lotfi Achour - lotfiachour@yahoo.fr; Damien Paineau - d.paineau@nutri-health.eu; Michel Riottot - Michel.Riottot@ibaic.u-psud.fr; Alain Attar - alain.attar@bjn.aphp.fr; Francis Bornet - frj.bornet@nutri-health.eu

* Corresponding author
\end{abstract}

Published: 5 December 2007

Nutrition Journal 2007, 6:42 doi:10.1 186/1475-289/-6-42
Received: 20 July 2007

Accepted: 5 December 2007

This article is available from: http://www.nutritionj.com/content/6/1/42

(c) 2007 Bouhnik et al; licensee BioMed Central Ltd.

This is an Open Access article distributed under the terms of the Creative Commons Attribution License (http://creativecommons.org/licenses/by/2.0), which permits unrestricted use, distribution, and reproduction in any medium, provided the original work is properly cited.

\begin{abstract}
Background: Short-chain fructo-oligosaccharides (scFOS) are increasingly used in human diet for their prebiotic properties. We aimed at investigating the effects of scFOS ingestion on the colonic microflora and oro-fecal transit time in elderly healthy humans.
\end{abstract}

Methods: Stools composition, oro-fecal transit time, and clinical tolerance were evaluated in 12 healthy volunteers, aged $69 \pm 2$ yrs, in three consecutive periods: basal period ( 2 weeks), scFOS $\left(\right.$ Actilight $\left.{ }^{\circledR}\right)$ ingestion period ( $8 \mathrm{~g} / \mathrm{d}$ for 4 weeks) and follow-up period (4 weeks). Two-way ANOVA, with time and treatment as factors, was used to compare the main outcome measures between the three periods.

Results: Fecal bifidobacteria counts were significantly increased during the scFOS period (9.17 \pm $0.17 \mathrm{log}$ cfu/g vs $8.52 \pm 0.26 \mathrm{log}$ cfu/g during the basal period) and returned to their initial values at the end of follow-up $(8.37 \pm 0.2 \mathrm{l}$ log cfu/g; $P<0.05)$. Fecal cholesterol concentration increased during the scFOS period $(8.18 \pm 2.37 \mathrm{mg} / \mathrm{g}$ dry matter vs $2.81 \pm 0.94 \mathrm{mg} / \mathrm{g}$ dry matter during the basal period) and returned to the baseline value at the end of follow-up $(2.87 \pm 0.44 \mathrm{mg} / \mathrm{g}$ dry matter; $\mathrm{P}<0.05$ ). Fecal $\mathrm{pH}$ tended to decrease during scFOS ingestion and follow-up periods compared to the basal period $(P=0.06)$. Fecal bile acids, stool weight, water percentage, and orofecal transit time did not change throughout the study. Excess flatus and bloating were significantly more frequent during scFOS ingestion when compared to the basal period $(P<0.05)$, but the intensity of these symptoms was very mild.

Conclusion: Four-week $8 \mathrm{~g} / \mathrm{d}$ scFOS ingestion is well tolerated and leads to a significant increase in fecal bifidobacteria in healthy elderly subjects. Whether the change in cholesterol metabolism found in our study could exert a beneficial action warrants further studies. 


\section{Background}

Short-chain fructo-oligosaccharides (scFOS) are a mixture of oligosaccharides consisting of glucose linked to fructose units [1]. They are poorly absorbed in the human small intestine [2], but are fermented in the colon by the resident microflora [3]. It is now well established that scFOS meet criteria to be considered as prebiotic, defined as a non digestible food ingredient that beneficially affects the host by selectively stimulating growth and/or activity of one or a limited number of colonic bacteria, and thus improves host health [4]. We have shown in humans that dietary addition of $10 \mathrm{~g} / \mathrm{d}$ scFOS led to increasing fecal counts of bifidobacteria [5]; moreover, the scFOS administration dose-dependently increases fecal bifidobacteria in healthy volunteers, with an optimal and well-tolerated dose ranging from 2.5 to $10 \mathrm{~g} / \mathrm{d}[6,7]$.

Bifidobacteria are considered beneficial to health [8], even if sound evidence of such effect is not available yet [4]. In mice, in vivo administered bifidobacteria along with fructo-oligosaccharides reduced 1,2-dimethylhydrazine induced carcinogenesis [9]. In rats, Bifidobacterium longum, administered alone or in association with non-digestible oligosaccharides, exerts strong antitumour activity $[10,11]$ This effect could be due to colon acidification that inhibits bacterial degradation of primary to carcinogenic secondary bile acids [12] and/or to increasing bifidobacteria population. Indeed, bifidobacteria per se could have an antitumorigenic activity. Bifidobacteria reduce nitrosamine mutagenicity, and Bifidobacterium bifidum administered along with Lactobacillus acidophilus to healthy humans decreases nitroreductase activity in stools [13]. Lastly, oligosaccharide ingestion could result in increasing colonic contents and decreasing transit time [14], both factors may affect colonic carcinogen concentration and mucosal contact time [15]. Thus, taking into account the intrinsic anti-tumoral properties of bifidobacteria and the effects on colonic $\mathrm{pH}$, fecal mass and transit time, a potential benefit of scFOS ingestion could be colon cancer prevention, in particular in the elderly, who are particularly at risk of developing colon cancer [16].

Although colonic microbiota is relatively stable throughout adult life, age-related changes in the gastrointestinal tract inevitably affect its composition [17]. Bifidobacteria are numerically important colonic species that can be found in adults [18], and the decline in bifidobacteria numbers is one of the most marked changes in the elderly gut [19]. These changes, along with general reduction in species diversity in most bacterial groups, as well as changes in diet and digestive physiology, such as intestinal transit time, may result in increased putrefaction in the colon, and greater susceptibility to disease. Dietary supplements containing prebiotics have been suggested to counteract these changes in the elderly [20-22].
In that context, the aim of our study was to assess in healthy elderly the effects of four-week scFOS ingestion on colonic microflora and oro-fecal transit time (OFTT).

\section{Methods \\ Subjects}

Twelve elderly healthy volunteers, six men and six women, aged $69 \pm 2$ years, participated in the study. None of them had any gastrointestinal disease history. No antibiotics or laxatives had been taken during the 3 months before the study. No other medication was allowed during the investigation period. The subjects signed a written informed consent to the protocol, which was approved by Lariboisière - Saint-Louis Hospital Ethics Committee.

\section{Study Design}

The study was conducted in Saint-Lazare Hospital, Paris, France. It was divided into three periods: basal (weeks 1-2), scFOS (weeks 3-6), and follow-up (weeks 7-10) periods. Throughout the study, volunteers took their usual diet. Neither fermented dairy products containing viable bifidobacteria and FOS (onions, asparagus, rye, and Jerusalem artichoke) were allowed, nor food known to induce abdominal symptoms (beans, cabbage, raisin, banana, and wheat bran). During scFOS period, subjects received $8 \mathrm{~g} / \mathrm{d}$ scFOS in two oral doses at the end of breakfast and diner. This dose was defined as a good compromise between efficacy and tolerance. We used scFOS from Actilight $^{\circledast}$ (Beghin Meiji, Marckolsheim, France), which consist of $44 \%$ 1-ketose $\left(\mathrm{GF}_{2}\right), 46 \%$ nystose $\left(\mathrm{GF}_{3}\right)$, and $10 \% 1^{\mathrm{F}}-\beta$-fructofuranosyl nystose $\left(\mathrm{GF}_{4}\right)$.

To measure the mean oro-fecal transit time (OFTT), the subjects ingested, with their breakfast, 20 radio-opaque pellets of different shapes for three consecutive days [23]. The first stools passed after the fourth day were collected, and their marker content analysed. Stools had been collected for three consecutive days before the end of weeks 2 (basal period), 6 (ingestion period), and 10 (follow-up period), that is to say at the end of each feeding period.

Tolerance to administered scFOS was evaluated using a daily chart in which the symptoms (excessive flatus, borborygmi, bloating, and abdominal pain) were rated from zero (no symptom) to three (severe symptom). Stool frequency and consistency were also graded by the volunteers. Diarrhoea was defined as one or more watery stools, or more than three stools per day.

\section{Stool collection}

Stools were collected three times, for $48 \mathrm{~h}$ at the end of each period (weeks 2, 6, and 10). Samples were collected in plastic containers rendered anaerobic (Anaerocult A; Merck, Darmstadt, Germany), immediately transferred to the laboratory, and then analysed for bacterial counts and 
$\mathrm{pH}$ within 2 hours. Stools were then frozen at $-20^{\circ} \mathrm{C}$ for further analysis.

\section{Bacterial counts and $\mathrm{pH}$}

Fresh faecal samples $(1 \mathrm{~g})$ were introduced in the first preweighed tube of the dilution series and thoroughly mixed, then further tenfold dilutions were made up to -9 in a reduced diluent ( $1 / 4$ strength cysteinated Ringer diluent). $0.1 \mathrm{ml}$ of each dilution was spread on plates with different selective media to distinguish several bacterial genera: total anaerobic counts (Wilkins-Chalgren agar), Bifidobacterium (Beerens' medium), Clostridium spp. (TNS medium), and enterobacteria (McConkey agar). The tests were duplicated for the first two media. Plates of the first three media were anaerobically incubated for 5 to $7 \mathrm{~d}$, and McConkey agar was aerobically incubated for 48 hours. Colony counts were obtained and expressed as a log of the colony-forming units (CFU) per gram of fresh faeces. Extemporarily, the fresh stool $\mathrm{pH}$ was measured by $\mathrm{pH}$ meter (Bioblock, Illkirch, France).

\section{Bile acids}

For bile acid and neutral sterol analysis, frozen stools had been lyophilised and lipids had been extracted with ethanol for 24 hours in a Soxhlet apparatus. Lipid fractions had been saponified in boiling ethanolic $2 \mathrm{~m}$ potassium hydroxide for $1 \mathrm{~h}$. Sterols were extracted with hexane, and bile acids were deconjugated. [24] Total bile acids were measured by 3-hydroxy-steroid-dehydrogenase, according to slight modification of Stempfel and Sidbury technique [25]. Prior to enzyme determination, bile acids were dissolved in 2-propanol. Free bile acids were methylated with diazomethane, silylated with Deriva-sil (Chrompack, Middelburg, The Netherlands), and assayed on Carlo Erba (Milan, Italy) HGRC 5160 gas chromatograph equipped with standard fused silica WCOT capillary column cross-linked with OV1701 (Spiral, Dijon, France) (length, $25 \mathrm{~m}$; film thickness, $0.2 \mathrm{~lm}$; oven temperature, $240^{\circ} \mathrm{C}$; hydrogen carrier gas flow rate, $2 \mathrm{~mL} /$ $\mathrm{min})$. Faecal sterols were silylated with bis(trimethylsilyl)tri-fluoroacetamide (BSTFA) + $1 \%$ trimethylchlorosilane (TMCS) (Pierce, Rockford, IL, USA), and quantified using gas chromatography described above, with the following modifications: fused silica WCOT OV 101 capillary column (Spiral, Dijon, France) (length, $25 \mathrm{~m}$; film thickness, $0.2 \mathrm{~lm}$; oven temperature, $220^{\circ} \mathrm{C}$ ).

\section{Data analysis}

Faecal bacteria concentrations were expressed as log colony forming unit (cfu)/g wet weight. The results were expressed as means \pm SEM for each period. Two-way ANOVA, with time and treatment as factors, was used to compare bacterial concentrations, $\mathrm{pH}$, and faecal metabolites between the three periods. Following a significant $\mathrm{F}$ test $(P<0.05)$, Newman-Keuls test was used to identify differences between individual means. Symptoms experienced with scFOS were compared to those experienced with placebo using Wilcoxon signed rank test.

\section{Results}

\section{Bacterial counts and $\mathrm{pH}$}

Table 1 summarises bacterial counts and $\mathrm{pH}$ during basal, scFOS, and follow-up periods. Faecal bifidobacteria counts were significantly increased during the scFOS period $(9.17 \pm 0.17 \log \mathrm{cfu} / \mathrm{g}$ vs $8.52 \pm 0.26 \log \mathrm{cfu} / \mathrm{g}$ during the basal period; $\mathrm{P}<0.05)$, and returned to their baseline values during the follow-up period $(8.37 \pm 0.21 \mathrm{log}$ $\mathrm{cfu} / \mathrm{g}$ ). Total anaerobe counts did not change during scFOS period compared to the basal period, but decreased in the follow-up period compared to the ingestion period $(\mathrm{P}<0.05)$. Faecal Clostridium counts were significantly increased during the follow-up period compared to the basal and scFOS periods $(\mathrm{P}<0.05)$. Faecal enterobacteria counts did not change during the three periods. Faecal pH tended to decrease during scFOS and follow-up periods compared to the basal period $(\mathrm{P}=0.06)$.

\section{Faecal neutral sterols and bile acids}

Faecal cholesterol concentration increased during the scFOS period $(8.18 \pm 2.37 \mathrm{mg} / \mathrm{g}$ dry matter vs $2.81 \pm 0.94$ $\mathrm{mg} / \mathrm{g}$ dry matter during the basal period; $\mathrm{P}<0.05)$ ), and returned to the baseline value during the follow-up period $(2.87 \pm 0.44 \mathrm{mg} / \mathrm{g}$ dry matter (figure 1$)$. However, no statistical differences were reported for coprostanol, cholestanol, and ketones for the three periods (Table 2). Total neutral sterol concentrations and outputs did not change, but tended to increase $(\mathrm{p}=0.08)$ during the scFOS period.

Total bile acid concentrations and outputs were similar in the three periods. Concentrations of secondary (lithocholic and deoxycholic acids) and primary bile acids (cholic and chenodeoxycholic acids) did not change for the three periods (Table 2).

Table I: Faecal bacterial counts (log cfu/g wet weight) and $\mathrm{pH}$ in elderly healthy volunteers during basal ( 2 wks), scFOS ( 4 wks) and follow-up ( 4 wks) periods $(n=12$, mean \pm SEM)

\begin{tabular}{cccc}
\hline & Basal period & scFOS period & $\begin{array}{c}\text { Follow-up } \\
\text { period }\end{array}$ \\
\hline Bifidobacteria & $8.52 \pm 0.26$ & $9.17 \pm 0.17^{\mathrm{a}}$ & $8.37 \pm 0.21$ \\
Total anaerobes & $10.09 \pm 0.07$ & $10.22 \pm 0.06^{\mathrm{b}}$ & $9.94 \pm 0.09$ \\
$\quad$ Clostridium & $3.25 \pm 0.25$ & $3.45 \pm 0.26^{\mathrm{b}}$ & $4.29 \pm 0.30^{\mathrm{c}}$ \\
Enterobacteria & $7.69 \pm 0.21$ & $7.45 \pm 0.28$ & $7.48 \pm 0.24$ \\
PH & $6.57 \pm 0.10$ & $6.32 \pm 0.10$ & $6.26 \pm 0.07$ \\
\hline
\end{tabular}

\footnotetext{
a different from basal and follow-up periods $(P<0.05)$

b different from follow-up period $(P<0.05)$

c different from basal period $(P<0.05)$
} 


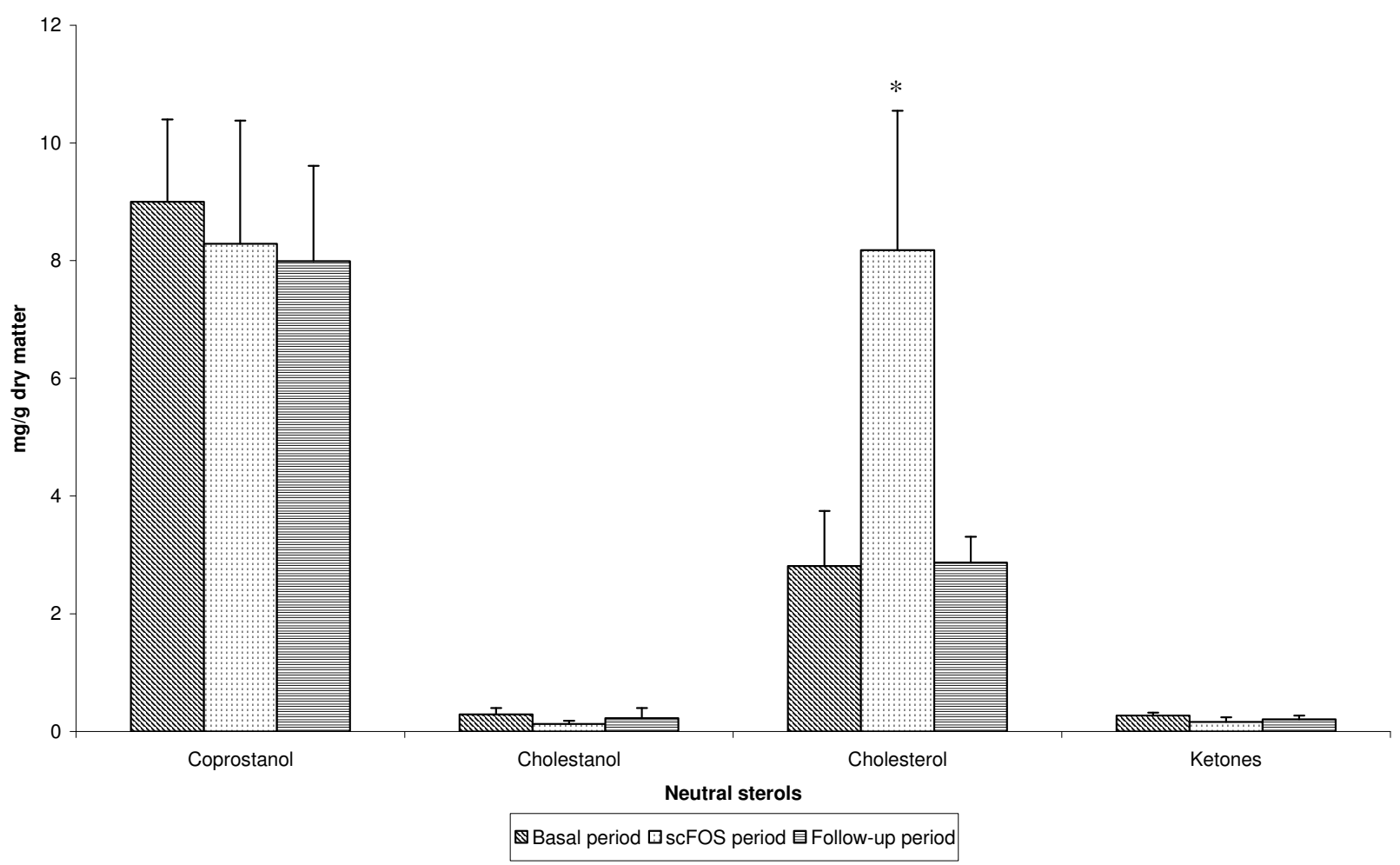

Figure I

Effect of 4-wk scFOS ingestion $(8 \mathrm{~g} / \mathrm{d})$ on faecal cholesterol in healthy volunteers $(\mathrm{means} \pm \mathrm{SEM}, \mathrm{n}=\mathrm{I} 2)$. *P < 0.05 between scFOS period and both basal and follow-up period

\section{Stool weight and oro-fecal transit time}

Stool wet weight, dry matter, and faecal water did not change throughout the study. Oro-fecal transit time was

Table 2: Faecal neutral sterols and bile acids ( $\mathrm{mg} / \mathrm{g}$ dry matter) in elderly healthy volunteers during the basal ( $2 \mathrm{wks}$ ), scFOS ( $4 \mathrm{wks}$ ) and follow-up ( 4 wks) periods $(n=12$, mean \pm SEM)

\begin{tabular}{|c|c|c|c|}
\hline Neutral sterols & Basal period & scFOS period & $\begin{array}{c}\text { Follow-up } \\
\text { period }\end{array}$ \\
\hline Coprostanol & $9.00 \pm 1.40$ & $8.29 \pm 2.09$ & $7.99 \pm 1.62$ \\
\hline Cholestanol & $0.29 \pm 0.11$ & $0,13 \pm 0.05$ & $0.23 \pm 0.17$ \\
\hline Cholesterol & $2.81 \pm 0.94^{a}$ & $8.18 \pm 2.37 b$ & $2.87 \pm 0.44^{a}$ \\
\hline Ketones & $0.27 \pm 0.05$ & $0.16 \pm 0.08$ & $0.21 \pm 0.06$ \\
\hline Total & $12.38 \pm 1.15$ & $16.75 \pm 1.94$ & $11.30 \pm 1.57$ \\
\hline Bile acids & Basal period & scFOS period & $\begin{array}{c}\text { Follow-up } \\
\text { period }\end{array}$ \\
\hline Lithocholic & $2.00 \pm 0.43$ & $1.29 \pm 0.29$ & $1.26 \pm 0.17$ \\
\hline Deoxycholic & $1.80 \pm 0.35$ & $2.58 \pm 0.50$ & $2.61 \pm 0.63$ \\
\hline Cholic & $0.46 \pm 0.21$ & $0.58 \pm 0.19$ & $0.87 \pm 0.24$ \\
\hline Chenodeoxycholic & $0.24 \pm 0.05$ & $0.20 \pm 0.04$ & $0.30 \pm 0.07$ \\
\hline Ketones & $1.26 \pm 0.30$ & $1.52 \pm 068$ & $1.33 \pm 0.19$ \\
\hline Total & $5.77 \pm 0.66$ & $6.17 \pm 1.25$ & $6.37 \pm 1.02$ \\
\hline
\end{tabular}

$a \neq b: P<0.05$ not significantly modified by scFOS ingestion compared to the basal and follow-up periods (Table 3 ).

\section{Digestive tolerance}

During scFOS ingestion, excessive flatus and bloating were significantly more frequent when compared to the basal period $(\mathrm{P}<0.05)$, but symptom intensity was very mild (Table 4). Borborygmi and abdominal pain were not significantly different in all periods.

\section{Discussion}

The present experiment showed that four-week scFOS ingestion, with a dose of $8 \mathrm{~g} / \mathrm{d}$, is well tolerated and leads

Table 3: Mean oro-fecal transit time (OFTT) and mean 24-h faecal wet weight, dry weight and percentage of faecal water in elderly healthy volunteers during the basal ( 2 wks), scFOS (4 wks) and follow-up ( 4 wks) periods $(n=12$, mean \pm SEM)

\begin{tabular}{cccc}
\hline & Basal period & scFOS period & $\begin{array}{c}\text { Follow-up } \\
\text { period }\end{array}$ \\
\hline OFTT $(\mathrm{h})$ & $37.2 \pm 3.4$ & $39.9 \pm 3.3$ & $37.8 \pm 3.7$ \\
Wet weight $(\mathrm{g} / \mathrm{d})$ & $155.4 \pm 20.9$ & $137.7 \pm 17.3$ & $174.8 \pm 22.0$ \\
Dry weight (g/d) & $32.8 \pm 3.3$ & $28.8 \pm 2.9$ & $35.2 \pm 3.5$ \\
Faecal water (\%) & $77 \pm 2$ & $77 \pm 1$ & $76 \pm 2$ \\
\hline
\end{tabular}


Table 4: Digestive symptom intensity (ranged from 0 to 3 ) in elderly health volunteers during the basal ( $2 \mathrm{wks}$ ), scFOS (4 wks) and follow-up ( 4 wks) periods $(n=12$, mean \pm SEM)

\begin{tabular}{cccc}
\hline & Basal period & scFOS period & $\begin{array}{c}\text { Follow-up } \\
\text { period }\end{array}$ \\
\hline $\begin{array}{c}\text { Excessive flatus } \\
\text { Bloating }\end{array}$ & 0 & $0,83 \pm 0,3^{\mathrm{a}}$ & $0,25 \pm 0,13$ \\
$\begin{array}{c}\text { Borborygmi } \\
\text { Abdominal } \\
\text { pain }\end{array}$ & 0 & $0,67 \pm 0,26^{\mathrm{a}}$ & $0,33 \pm 0,14$ \\
\hline
\end{tabular}

Symptom intensity was rated as follow: 0 : no symptom ; I: mild symptoms; 2 : moderate symptoms; 3 : severe symptoms

a different from basal period $(P<0.05)$

to significant increase in faecal bifidobacteria and cholesterol excretion in healthy elderly. The sc-FOS bifidogenic effect has been extensively demonstrated in adults $[6,26-$ $28]$, but rarely in elderly $[19,21,22]$. Among the very few available studies about functional foods in elderly, one recent double-blind trial testing a symbiotic (B. lactis BL01, B. bifidum BB-02 and an inulin-based prebiotic) also found promising results [29]. Significant increase in total bifidobacteria counts was indeed observed in the symbiotic group compared with the placebo group.

We also found increasing Clostridium spp. after sc-FOS ingestion discontinuation. Clostridium spp. is a major component of normal anaerobic microflora and it can not be considered as a deleterious or beneficial genus. Since some toxinogenic subspecies of Clostridium difficile are related to an increased risk of pseudo membranous colitis and/or infection in older people, it would have been interesting to measure the sc-FOS effects on these subspecies. However, we did not perform those analyses, for they were out of our study scope. Further studies may investigate this point, using adequate measurement methods for species concentrations and toxinogenic properties (cellular cultures, biomolecular analysis). Culture-based enumeration of microbiota does not usually allow for bacterial species measurement, but mainly bacterial genus.

In our study, several parameters were assessed with the objective to better understand scFOS physiological effects in healthy elderly, such as transit time, stool characteristics, and colonic environment. We did not find scFOS ingestion changed faecal weight and oro-fecal transit time in elderly. Gibson et al. have shown that prebiotics can increase stool output: they studied 8 volunteers under controlled diet, and showed that with $15 \mathrm{~g} / \mathrm{d}$ fructo-oligosaccharides, stool output significantly increased from 136 to $154 \mathrm{~g} / \mathrm{d}$ [27]. Other two human studies did not demonstrate increasing stool output $[2,30]$. but the diet was not controlled in none of these studies, which may have hidden any slight effect. In the study of Alles et al., 12 healthy subjects were given $4.8-19.2 \mathrm{~g} / \mathrm{d}$ oligomate $(52 \%$ galacto-oligosaccharides), which did not result in any change in bowel habit. However, the subjects started with unusually high faecal weights under controlled diet, 272 $\pm 26 \mathrm{~g} / \mathrm{d}$ On the other hand, studies using probiotics demonstrated bifidobacteria could reduce human colonic transit time, but not all bifidobacteria strains have the same effects [31]. This specific strain-dependent effect could explain the reason why our prebiotic, which stimulates global endogenous bifidobacteria, had no effect.

In our study, the microbial transformation of cholesterol into coprostanol was not influenced by scFOS ingestion. Another study observed that sterol and fatty acid biohydrogenation by intestinal microflora is altered by oligosaccharide fermentation [32]. Coprostanol production results from intestinal anaerobic bacteria action [33]. Concerning bile acid metabolism, no differences were observed during the three periods. Furthermore, the use of poorly digestible carbohydrates in rats, hamsters and pigs demonstrated that prevention of microbial conversion of bile acids depended on the carbohydrate dose in the diet $[23,34]$ This suggests that the low carbohydrate dose, $8 \mathrm{~g} /$ d scFOS, used in this experiment is unable to modify microbial conversion of bile acids.

Endogenous or exogenous bile acids, as well as dietary cholesterol are carcinogenic factors involved in colon cancer in laboratory animals $[35,36]$ Various epidemiological studies suggest those steroids could also be involved in colon cancer in men $[12,37]$. According to these studies, low scFOS dose ingestion by humans, which prevented microbial conversion of cholesterol into cytotoxic molecule, (coprostanol, potentially carcinogenetic), could be interesting for humans. In our study, the intake of $8 \mathrm{~g} / \mathrm{d}$ scFOS led to increasing faecal cholesterol. The mechanism of such increase could be related to decreasing cholesterol bacterial transformation, although we failed to find any significant sc-FOS effect on cholesterol bacterial metabolism. Moreover, the low scFOS dose used in our study was also probably not sufficient to significantly reduce microbial conversion of bile acids. However, in our previous study evaluating a higher scFOS dose $(12.5 \mathrm{~g} / \mathrm{d})$, we also failed to show any significant effect in bile acids and neutral sterol [28]. These negative results could be explained by a questionable capacity of various bifidobacteria to take up cholesterol into their cellular membrane [38].

\section{Conclusion}

Overall, we showed that $8 \mathrm{~g} / \mathrm{d}$ scFOS ingested are well tolerated and led to significant increase in faecal bifidobacteria in healthy elderly. Under our experimental conditions, i.e. $8 \mathrm{~g} / \mathrm{d}$ for 12 days, we failed to show any sc-FOS effects on OFTT, which is commonly increased in elderly living 
in industrialised countries. We found significant change in cholesterol metabolism, which could potentially exert protective action against colon cancer; however, this finding warrants further studies.

\section{List of abbreviations used}

OFTT: Oro-fecal transit time; scFOS: Short-chain fructooligosaccharides

\section{Competing interests}

The author(s) declare that they have no competing interests.

\section{Authors' contributions}

YB participated in the study design, data collection, data analysis, and manuscript writing. LA participated in data collection. MR carried out bile acids and neutral sterols analysis. DP participated in data analysis and manuscript writing. FB designed the study and participated in manuscript writing. All authors read and approved the final manuscript.

\section{Acknowledgements}

The study was supported by a grant from Beghin-Meiji, Marckolsheim, France.

\section{References}

I. Hirayama M, Sumi N, Hidaka H: Purification and properties of fructo-oligosaccharides producing beta-fructofuranosidase from Aspergillus niger ATCC 206I I. Agric Biol Chem ; : 1989, 53:667-673.

2. Alles MS, Hautvast JG, Nagengast FM, Hartemink R, Van Laere KM, Jansen JB: Fate of fructo-oligosaccharides in the human intestine. BrJ Nutr 1996, 76:21I-22I.

3. Molis C, Flourie B, Ouarne F, Gailing MF, Lartigue S, Guibert A, Bornet $F$, Galmiche JP: Digestion, excretion, and energy value of fructooligosaccharides in healthy humans. Am J Clin Nutr 1996, 64:324-328.

4. Gibson GR, Roberfroid MB: Dietary modulation of the human colonic microbiota: introducing the concept of prebiotics. J Nutr 1995, 125: |401-1412.

5. Bouhnik Y, Raskine L, Simoneau G, Vicaut E, Neut C, Flourié B, Brouns $F$, Bornet $F$ : The capacity of nondigestible carbohydrates to stimulate fecal bifidobacteria in healthy humans: a double-blind, randomized, placebo-controlled, parallelgroup, dose-response relation study. Am J Clin Nutr 2004, 6: $1658-1664$.

6. Bouhnik Y, Vahedi K, Achour L, Attar A, Salfati J, Pochart P, Marteau $P$, Flourie B, Bornet F, Rambaud JC: Short-chain fructo-oligosaccharide administration dose-dependently increases fecal bifidobacteria in healthy humans. J Nutr 1999, 129:1 13-116.

7. Bouhnik Y, Raskine L, Simoneau G, Paineau D, Bornet F: The capacity of short-chain fructo-oligosaccharides to stimulate faecal bifidobacteria: a dose-response relationship study in healthy humans. Nutr 」 2006, 5:8.

8. Roberfroid MB: Health benefits of non-digestible oligosaccharides. Adv Exp Med Biol 1997, 427:211-219.

9. Koo M, Rao AV: Long-term effect of Bifidobacteria and Neosugar on precursor lesions of colonic cancer in CFI mice. Nutr Cancer 1991, 16:249-257.

10. Singh J, Rivenson A, Tomita M, Shimamura S, Ishibashi N, Reddy BS: Bifidobacterium longum, a lactic acid-producing intestinal bacterium inhibits colon cancer and modulates the intermediate biomarkers of colon carcinogenesis. Carcinogenesis 1997, 18:833-841.

II. Challa A, Rao DR, Chawan CB, Shackelford L: Bifidobacterium longum and lactulose suppress azoxymethane-induced colonic aberrant crypt foci in rats. Carcinogenesis 1997, 18:517-52|.

12. Nair PP: Role of bile acids and neutral sterols in carcinogenesis. Am J Clin Nutr 1988, 48:768-774.

13. Marteau P, Pochart P, Flourie B, Pellier P, Santos L, Desjeux JF, Rambaud JC: Effect of chronic ingestion of a fermented dairy product containing Lactobacillus acidophilus and Bifidobacterium bifidum on metabolic activities of the colonic flora in humans. Am J Clin Nutr 1990, 52:685-688.

14. El Oufir L, Flourie B, Bruley V, Barry JL, Cloarec D, Bornet F, Galmiche JP: Relations between transit time, fermentation products, and hydrogen consuming flora in healthy humans. Gut 1996, 38:870-877.

15. Cummings JH, Bingham SA, Heaton KW, Eastwood MA: Fecal weight, colon cancer risk, and dietary intake of nonstarch polysaccharides (dietary fiber). Gastroenterology 1992, 103:1783-1789.

16. Miller K, Waye JD: Colorectal polyps in the elderly: what should be done? Drugs Aging 2002, 19:393-404.

17. Woodmansey E], McMurdo ME, Macfarlane GT, Macfarlane S: Comparison of compositions and metabolic activities of fecal microbiotas in young adults and in non-antibiotic-treated elderly subjects. Appl Env Microbiol 2004, 70:6 | | 3-6 I 22.

18. Finegold SM, Sutter VL, Mathisen GE: Normal indigenous intestinal flora. In Human intestinal microflora in health and disease Edited by: Hentges DJ. New York, Academic Press; 1983:3-31.

19. Woodmansey EJ: Intestinal bacteria and ageing. J Appl Microbiol 2007, 102:1 178-1186.

20. Bunout D, Hirsch S, Pia de la Maza M, Munoz C, Haschke F, Steenhout P, Klassen P, Barrera G, Gattas V, Petermann M: Effects of prebiotics on the immune response to vaccination in the elderly. JPEN J Parenter Enteral Nutr 2002, 26:372-376.

21. Hamilton-Miller JM: Probiotics and prebiotics in the elderly. Postgrad Med J 2004, 80:447-45।.

22. Mitsuoka T, Hidaka $\mathrm{H}$, Eida T: Effect of fructo-oligosaccharides on intestinal microflora. Nahrung 1987, 31:427-436.

23. Cummings JH, Wiggins HS: Transit through the gut measured by analysis of a single stool. Gut 1976, 17:219-223.

24. Riottot M, Olivier P, Huet A, Caboche J], Parquet M, Khallou J, Lutton $C:$ Hypolipidemic effects of beta-cyclodextrin in the hamster and in the genetically hypercholesterolemic Rico rat. Lipids 1993, 28: $181-188$.

25. Stempfel RSJ, Sidbury JBJ: Studies with the hydroxysteroid dehydrogenases. i. a simplified method for the enzymatic estimation of 3- and 17-hydroxysteroids. J Clin Endocrinol Metab 1964, 24:367-374.

26. Tuohy KM, Kolida S, Lustenberger AM, Gibson GR: The prebiotic effects of biscuits containing partially hydrolysed guar gum and fructo-oligosaccharides--a human volunteer study. $\mathrm{Br} J$ Nutr 200I, 86:34I-348.

27. Gibson GR, Beatty ER, Wang X, Cummings JH: Selective stimulation of bifidobacteria in the human colon by oligofructose and inulin. Gastroenterology 1995, 108:975-982.

28. Bouhnik Y, Flourie B, Riottot M, Bisetti N, Gailing MF, Guibert A, Bornet $F$, Rambaud JC: Effects of fructo-oligosaccharides ingestion on fecal bifidobacteria and selected metabolic indexes of colon carcinogenesis in healthy humans. Nutr Cancer 1996, 26:2I-29.

29. Bartosch S, Woodmansey EJ, Paterson JCM, McMurdo ME, Macfarlane GT: Microbiological effects of consuming a synbiotic containing Bifidobacterium bifidum, Bifidobacterium lactis, and oligofructose in elderly persons, determined by real-time polymerase chain reaction and cunting of viable bacteria. Clin Infect Dis 2005, 40:28-37.

30. Ito $M$, Deguchi $Y$, Miyamori A: Effects of administration of galacto-oligosaccharides on the human faecal microflora, stool weight and abdominal sensation. Microb Ecol Healt Dis 1990, 3:285-292.

31. Picard C, Fioramonti J, Francois A, Robinson T, Neant F, C M: Review article: bifidobacteria as probiotic agents -- physiological effects and clinical benefits. Aliment Pharmacol Ther 2005, 22:495-512.

32. Eyssen H, Parmentier G: Biohydrogenation of sterols and fatty acids by the intestinal microflora. Am J Clin Nutr 1974, 27:1329-1340. 
33. Hill MJ: Faecal steroids in the etiology of large bowel cancer. In The Bile Acids Edited by: Nair PP KD. New York, Plenum; 1976:169-200.

34. Andrieux C, Gadelle D, Leprince C, Sacquet E: Effects of some poorly digestible carbohydrates on bile acid bacterial transformations in the rat. Br J Nutr 1989, 62:103-119.

35. Hori T, Matsumoto K, Sakaitani Y, Sato M, Morotomi M: Effect of dietary deoxycholic acid and cholesterol on fecal steroid concentration and its impact on the colonic crypt cell proliferation in azoxymethane-treated rats. Cancer Lett 1998, 124:79-84.

36. Narisawa T, Magadia NE, Weisburger JH, Wynder EL: Promoting effect of bile acids on colon carcinogenesis after intrarectal instillation of $\mathbf{N}$-methyl-N'-nitro-N-nitrosoguanidine in rats. J Natl Cancer Inst 1974, 53:1093-1097.

37. Breuer NF, Goebell H: Bile acids and cancer of the large bowel. Dig Dis 1987, 5:65-77.

38. Pereira DIA, Gibson GR: Cholesterol Assimilation by Lactic Acid Bacteria and Bifidobacteria Isolated from the Human Gut. Appl Environ Microbiol 2002, 68:4689-4693.

Publish with Biomed Central and every scientist can read your work free of charge

"BioMed Central will be the most significant development for disseminating the results of biomedical research in our lifetime. "

Sir Paul Nurse, Cancer Research UK

Your research papers will be:

- available free of charge to the entire biomedical community

- peer reviewed and published immediately upon acceptance

- cited in PubMed and archived on PubMed Central

- yours - you keep the copyright

Submit your manuscript here:

http://www.biomedcentral.com/info/publishing_adv.asp 